\title{
Pengaruh Partisipasi Pemakai Sistem Informasi, Kemampuan Pemakai Sistem Informasi, Ukuran Organisasi Terhadap Kinerja Sistem Informasi Akuntansi
}

\author{
Indra Fatmawati ${ }^{*}$, Dwi Cahyono ${ }^{2}$, Astrid Maharani ${ }^{3}$
}

1,2,3 Universitas Muhammadiyah Jember

\author{
A R T I C L E I N F O \\ Article history: \\ Received 19 August 2018 \\ Received in revised form \\ 16 September 2018 \\ Accepted 15 October 2018 \\ Available online 26 \\ November 2018 \\ Kata Kunci: \\ Partisipasi informasi sistem \\ pengguna, kemampuan \\ pengguna sistem informasi, \\ ukuran organisasi dan \\ kinerja sistem informasi \\ akuntansi \\ Keywords: \\ User system information \\ participation, information \\ system user capability, \\ organizational size and \\ performance of accounting \\ information systems
}

\begin{abstract}
A B S T R A K
Penelitian ini bertujuan untuk menganalisis pengaruh partisipasi sistem informasi pengguna, kemampuan pengguna sistem informasi, ukuran organisasi terhadap kinerja sistem informasi akuntansi (studi empiris pada OPD (organisasi daerah Kabupaten Lumajang). Dalam penelitian ini adalah karyawan / karyawan \& karyawan pengguna teknologi informasi di Kantor Wilayah (Perangkat Daerah) Kabupaten Lumajang, berjumlah 50 orang. Metode analisis data yang digunakan adalah metode analisis regresi linier berganda. Uji hipotesis yang digunakan adalah uji t, uji $\mathrm{F}$ dan koefisien tekad. Hasil penelitian menunjukkan bahwa partisipasi pengguna sistem informasi berpengaruh pada kinerja SIA (Organisasi Perangkat Daerah) OPD Kabupaten Lumajang. Kemampuan pengguna sistem mempengaruhi kinerja SIA (Organisasi Perangkat Daerah) Kabupaten Lumajang. Ukuran organisasi memengaruhi kinerja OPD SIA (Organisasi Perangkat Daerah) Kabupaten Lumajang.
\end{abstract}

\section{A B S T R A C T}

This study aims to analyze the influence of user information system participation, the ability of users of information systems, organizational size on the performance of accounting information systems (empirical studies on OPD (regional organizations of Lumajang Regency). in this study were employees / employees \& employees of information technology users in the Regional Office (Regional Devices) of Lumajang Regency, amounting to 50 people.The data analysis method used was the method of multiple linear regression analysis. The hypothesis test used was the t test, $F$ test and coefficient of determination. The results of the study show that the participation of users of information systems had an effect on the performance of the SIA (Regional Device Organization) OPD of the Regency of Lumajang. The ability of system users affects the performance of the SIA (Regional Device Organization) of Lumajang Regency. Organizational size influences the performance of the SIA (Regional Device Organization) OPD of Lumajang Regency.

\footnotetext{
* Corresponding author.

E-mail addresses: indrafatmawati170@yahoo.com (Indra Fatmawati)
} 


\section{Pendahuluan}

Dalam era globalisasi, persaingan, perubahan dan ketidakpastian antar bidang usaha mewarnai kehidupan lingkungan bisnis yang semakin ketat. Agar suatu badan usaha atau perusahaan dapat tetap bertahan, perlu adanya perbaikan untuk meningkatkan usaha. Persaingan bisnis yang semakin meningkat ini menuntut perusahaan untuk dapat memanfaatkan kemampuan yang ada dengan sebaik mungkin. Manajemen dalam suatu perusahaan perlu untuk mengidentifikasi masalah, menyeleksi, menganalisis suatu proses penyesuaian dengan tepat untuk mendapatkan peluang agar dapat unggul dari pesaingnya. Dalam pengembangan sistem informasi sangat tergantung pada kesesuaian harapan antara sistem analyst, pemakai (user), sponsor dan customer (Szajna dan Scammell 1993). Perubahan dari sistem manual ke sistem komputerisasi tidak hanya menyangkut perubahan teknologi tetapi juga perubahan perilaku dan organisasi (Hopwood 1995). Perubahan perilaku dan organisasi ini dapat berupa resistency to change. Oleh karena itu pengembangan sistem informasi memerlukan suatu perencanaan dan implementasi yang hati-hati, untuk menghindari adanya penolakan terhadap sistem yang dikembangkan (resistency to change) maka diperlukan adanya partisipasi dari pemakai (Ginzberg, 1981).

Penggunaan teknologi telematika menghasilkan simplikasi hubungan antara masyarakat dan pemerintah, yaitu dalam bentuk G2C (Government to Citizen), G2B (Government to Business) dan G2G (Government to Government). Tak terkecuali di Kabupaten Lumajang yang sistem informasi akuntansi (SIA) dalam pencatatan serta penyusunan laporan keuangan sudah menggunakan software e-finance sejak tahun 2015. Namun masih terdapat beberapa kelemahan seperti adanya indikasi penyalahgunaan kecanggihan alat sehinggan mengakibatkan masalah dan kurangnya sosialisasi tentang pentingnya sistem informasi sehingga beberapa data antar instansi ada yang masih belum sinkron. Kelemahan Sistem Informasi Akuntansi Pemerintah Kabupaten Lumajang terdapat beberapa kasus sehingga mengakibatkan Tahun 2017 turun kelas dalam opini laporan keuangan menjadi Wajar Dengan Pengecualian (WDP) setelah tiga tahun berturut-turut WTP mulai dari tahun 2014-2016. Oleh sebab itu, peneliti memiliki ketertarikan untuk meneliti melihat bagaimana pengaruh partisipasi pemakai sistem informasi, kemampuan pemakai sistem informasi, ukuran organisasi terhadap kinerja sistem informasi akuntansi pada Organisasi Perangkat Daerah (OPD) di Kabupaten Lumajang.

Berdasarkan latar belakang di atas maka rumusan masalah dalam penelitian ini adalah: a) Apakah partisipasi pemakai sistem informasi berpengaruh terhadap kinerja SIA?, b) Apakah kemampuan pemakai sistem informasi berpengaruh terhadap kinerja SIA?, dan c) Apakah ukuran organisasi berpengaruh terhadap kinerja SIA

\section{Metode}

Jenis data yang digunakan pada penelitian ini adalah data subyek. Sumber data pada penelitian ini adalah data primer. Variabel dependen dalam penelitian ini adalah Kinerja Sistem Informasi Akuntansi. Kinerja merupakan gambaran mengenai tingkat pencapaian pelaksanaan satu kegiatan dalam periode tertentu. Kinerja dalam organisasi merupakan jawaban dari berhasil atau tidaknya tujuan organisasi yang telah ditetapkan. Penelitian yang dilakukan komara (2005) menyebutkan 2 kategori untuk menilai suatu kinerja sistem informasi akuntansi yaitu: 1. Kepuasan pemakai sistem informasi pada isi SIA, 2. Kepuasan pemakai sistem informasi pada akurasi SIA, 3. Kepuasan pemakai sistem informasi pada format SIA, 4. Banyaknya penggunaan/durasi, 5. Kerutinan penggunaan.

Variabel independen dalam penelitian ini yakni Partisipasi Pemakai Sistem Informasi, Kemampuan pemakai sistem dan Ukuran Organisasi.

a. Partisipasi Pemakai Sistem Informasi (X1)

Menurut Olson \& Ives dalam Choe dalam Komara (2005). Keterlibatan pengguna merupakan keterlibatan dalam proses pengembangan sistem oleh anggota organisasi atau anggota dari kelompok pengguna target.

Indikator yang digunakan (Susanto, 2008): 1) Ikut serta berpartisipasi dalam pengembangan sistem informasi, 2) Meningkatkan hubungan antara user dan manajemen, 3) Merasa memiliki dan turut menjaga atas sistem yang dibangun, 4) Menghasilkan sistem informasi yang bernilai, 5) Memberikan kepuasan bagi manajemen

b. Kemampuan pemakai sistem (X2)

Menurut Robbins mendefinisikan kemapuan (ability) yang dialih bahasakan oleh Diana Angelica adalah sebagai berikut: "Kemampuan adalah kecakapan atau potensi menguasai suatu keahlian yang merupakan bawaan sejak lahir atau merupakan hasil latihan atau praktek dan digunakan untuk mengerjakan sesuatu yang diwujudkan melalui tindakannya". 
Indikator yang digunakan (Robins, 2008): 1) Memiliki pengetahuan sistem informasi akuntansi, 2) Memahami tugas dan pekerjaannya sebagai pemakai sistem informasi, 3) Mampu mengerjakan tugas dari pekerjaan yang menjadi tanggung jawab, 4) Mampu menyelaraskan pekerjaan dengan tugas, 5)

Ahli dalam pekerjaan yang menjadi tanggungjawab

c. Ukuran Organisasi (X3)

Menurut Choe, Jong-Min (1996, dalam Luciana Spica, 2007). "Ukuran organisasi dapat diukur oleh jumlah penjualan atau pendapatan jumlah pegawai dari suatu perusahaan."

Indikator yang digunakan (Partomo, 2004) : 1) Memiliki total asset lebih dari Rp. 5 milyar, 2) Unit kegiatan yang memiliki kekayaan bersih lebih besar dari Rp. 200 juta, 3) Memiliki pekerja di atas 2000 orang, 4) Rotasi pegawai dilakukan secara rutin sesuai aturan, 5) Memiliki beberapa unit kegiatan

Metode analisis data yang digunakan dalam penelitian ini adalah metode analisis statistik dengan persamaan regresi linier berganda dengan menggunakan aplikasi SPSS.

\section{Hasil dan pembahasan}

Gambaran Umum Objek Penelitian

Organisasi Perangkat Daerah (OPD) yang menjadi objek penelitian di sini adalah dinas yang ada di Kota Lumajang. Berdasarkan pasal 9 ayat (1) dan (2) dalam Peraturan Pemerintah (PP) No. 8 Tahun 2003 tentang Pedoman Organisasi Perangkat Daerah menyatakan bahwa Dinas Daerah Kabupaten/Kota merupakan unsur pelaksana Pemerintah Kabupaten/Kota dipimpin oleh seorang Kepala yang berada di bawah dan bertanggung jawab kepada Bupati/Walikota melalui Sekretaris Daerah. Dinas ini mempunyai tugas melaksanakan kewenangan desentralisasi. Sedangkan berdasarkan pasal 10 ayat (2) dan (5) pada Peraturan Pemerintah (PP) No. 8 Tahun 2003 menyatakan bahwa Lembaga Teknis Daerah Kabupaten/Kota merupakan unsur pelaksana tugas tertentu, dipimpin oleh seorang Kepala yang berada di bawah dan bertanggung jawab kepada Bupati/Walikota melalui Sekretaris Daerah, yang melaksanakan tugas tertentu karena sifatnya tidak tercakup oleh Sekretariat Daerah dan Dinas Daerah Kabupaten/Kota. Lembaga Teknis Daerah ini dapat berupa Badan, Kantor, dan Rumah Sakit Daerah. Berdasarkan gambaran umum di atas, maka penulis akan mengambil objek penelitian berupa Organisasi Perangkat Daerah (OPD) yang terdiri dari 5 Dinas yang ada di kota Lumajang.

Deskripsi hasil

Deskriptif Karakteristik Responden

Berikut ini disajikan statistik deskriptif untuk masing-masing variabel yang digunakan dalam penelitian ini dan data tentang karakteristik responden. Berikut ini disajikan statistik deskriptif untuk masing-masing variabel yang digunakan dalam penelitian ini dan data tentang karakteristik responden. Data yang digunakan dalam penelitian ini meliputi data-data sebagai berikut: Umur, Jenis Kelamin dan Pendikikan Terkahir. Data deskriptif responden sebagai berikut:

1. Karakteristik Responden Berdasarkan Umur

Tabel 1. Umur Responden

\begin{tabular}{ccc}
\hline Umur & Jumlah & Persentase (\%) \\
\hline $26-30$ tahun & 8 & 16 \\
$31-35$ tahun & 17 & 34 \\
$36-40$ tahun & 10 & 20 \\
$>40$ tahun & 15 & 30 \\
\hline Jumlah & 50 & $100 \%$ \\
\hline
\end{tabular}

Sumber : data primer diolah, 2018

Tabel 1. menunjukkan bahwa jumlah responden yang berumur $26-30$ tahun sebanyak 8 orang (16\%), 31 - 35 tahun sebanyak 17 orang (34\%), 36 - 40 tahun sebanyak 10 orang (20\%) dan > 40 tahun sebanyak 15 orang (30\%). 


\section{Jenis Kelamin}

Tabel 2. Jenis Kelamin Responden

\begin{tabular}{ccc}
\hline Jenis Kelamin & Jumlah & Persentase (\%) \\
\hline Laki-laki & 33 & 66 \\
Perempuan & 17 & 34 \\
\hline Jumlah & 50 & $100 \%$
\end{tabular}

Sumber : data primer diolah, 2018

Tabel 2. menunjukkan bahwa jumlah responden yang berjenis kelamin laki-laki yaitu sebanyak 33 orang (66\%), sedangkan yang berjenis kelamin perempuan yaitu sebanyak 17 orang (34\%).

3. Karakteristik Responden Berdasarkan Pendidikan Terakhir

Tabel 3. Pendidikan Responden

\begin{tabular}{ccc}
\hline Jenis Kelamin & Jumlah & Persentase (\%) \\
\hline S1 & 38 & 76 \\
S2 & 12 & 24 \\
\hline Jumlah & 50 & $100 \%$
\end{tabular}

Sumber : data primer diolah, 2018

Tabel 3 menunjukkan bahwa jumlah responden yang berpendidikan terakhir S1 yaitu sebanyak 38 orang (76\%) dan responden yang berpendidikan terakhir S2 yaitu sebanyak 12 orang (24\%).

Deskripsi Variabel Penelitian

Dari data distribusi frekuensi responden dapat dilihat seberapa besar nilai suatu variabel jika dibandingkan nilai variabel lain, serta bagaimana pola hubungan antar variabel yang ada dalam penelitian. Deskripsi Variabel Partisipasi Pemakai Sistem Informasi $\left(\mathrm{X}_{1}\right)$

Penilain responden terhadap variabel Partisipasi Pemakai Sistem Informasi $\left(\mathrm{X}_{1}\right)$, menurut klarifikasi tingkatan skor dari masing-masing pernyataan Partisipasi Pemakai Sistem Informasi dijelaskan pada tabel berikut ini:

Tabel 4. Distribusi Frekuensi Jawaban Responden Terhadap Partisipasi Pemakai Sistem Informasi

\begin{tabular}{|c|c|c|c|c|c|c|c|c|c|c|c|}
\hline \multirow{2}{*}{$\begin{array}{c}\text { Nomor } \\
\text { Pernyataan }\end{array}$} & \multicolumn{11}{|c|}{ Jawaban Responden } \\
\hline & 5 & $\%$ & 4 & $\%$ & 3 & $\%$ & 2 & $\%$ & 1 & $\%$ & Total \\
\hline 1 & 23 & 46 & 19 & 38 & 8 & 16 & - & - & - & - & 50 \\
\hline 2 & 12 & 24 & 29 & 59 & 9 & 18 & - & - & - & - & 50 \\
\hline 3 & 12 & 24 & 33 & 66 & 5 & 10 & - & - & - & - & 50 \\
\hline 4 & 11 & 22 & 32 & 64 & 6 & 12 & 1 & 2 & - & - & 50 \\
\hline 5 & 11 & 22 & 34 & 68 & 5 & 10 & - & - & - & - & 50 \\
\hline Rata-Rata & 13.8 & 27.6 & 29.4 & 59 & 6.6 & 13.2 & 1 & 2 & - & - & 50 \\
\hline
\end{tabular}

Sumber: Data diolah

Berdasarkan data Tabel 4 di atas, dapat diketahui bahwa penilaian terbanyak responden terhadap variabel Partisipasi Pemakai Sistem Informasi setuju, yaitu dengan presentasi jawaban pada indikator Ikut serta berpartisipasi dalam pengembangan sistem informasi sebesar 38\%, indikator Meningkatkan hubungan antara user dan manajemen sebesar 59\%, indikator Merasa memiliki dan turut menjaga atas sistem yang dibangun sebesar 66\%, indikator Menghasilkan sistem informasi yang bernilai sebesar 64\% dan indikator Memberikan kepuasan bagi manajemen sebesar 68\%. dari presentase masingmasing indikator diperoleh rata-rata sebesar 59\% pada penilaian kriteria jawaban setuju bahwa Partisipasi Pemakai Sistem Informasi Pada Organisasi Perangkat Daerah (OPD) di Kabupaten Lumajang baik dan sesuai. 
Deskripsi Variabel Kemampuan pemakai sistem $\left(\mathrm{X}_{2}\right)$

Penilain responden terhadap variabel Kemampuan pemakai sistem $\left(\mathrm{X}_{2}\right)$, menurut klarifikasi tingkatan skor dari masing-masing pernyataan Kemampuan pemakai system dijelaskan pada tabel berikut ini:

Tabel 5. Distribusi Frekuensi Jawaban Responden Terhadap Kemampuan Pemakai Sistem

\begin{tabular}{|c|c|c|c|c|c|c|c|c|c|c|c|}
\hline \multirow{2}{*}{$\begin{array}{c}\text { Nomor } \\
\text { Pernyataan }\end{array}$} & \multicolumn{11}{|c|}{ Jawaban Responden } \\
\hline & 5 & $\%$ & 4 & $\%$ & 3 & $\%$ & 2 & $\%$ & 1 & $\%$ & Tota \\
\hline 1 & 11 & 22 & 28 & 56 & 11 & 22 & - & - & - & - & 50 \\
\hline 2 & 16 & 32 & 26 & 52 & 8 & 16 & - & - & - & - & 50 \\
\hline 3 & 7 & 14 & 33 & 66 & 10 & 20 & - & - & - & - & 50 \\
\hline 4 & 8 & 16 & 33 & 66 & 9 & 18 & - & - & - & - & 50 \\
\hline 5 & 12 & 24 & 32 & 64 & 6 & 12 & - & - & - & - & 50 \\
\hline Rata-Rata & 10.8 & 21.6 & 30.4 & 60.8 & 8.8 & 17.6 & - & - & - & - & 50 \\
\hline
\end{tabular}

Sumber: Data diolah

Berdasarkan data Tabel 5 di atas, dapat diketahui bahwa penilaian terbanyak responden terhadap variabel Kemampuan Pemakai Sistem setuju, yaitu dengan presentasi jawaban pada indikator Memiliki pengetahuan sistem informasi akuntansi sebesar 56\%, indikator Memahami tugas dan pekerjaannya sebagai pemakai sistem informasi sebesar 52\%, indikator Mampu mengerjakan tugas dari pekerjaan yang menjadi tanggung jawab sebesar 66\%, indikator Mampu menyelaraskan pekerjaan dengan tugas sebesar $66 \%$ dan indikator Ahli dalam pekerjaan yang menjadi tanggungjawab sebesar $64 \%$. dari presentase masing-masing indikator diperoleh rata-rata sebesar $60,8 \%$ pada penilaian kriteria jawaban setuju bahwa Kemampuan Pemakai Sistem pada Organisasi Perangkat Daerah (OPD) di Kabupaten Lumajang baik dan sesuai.

Deskripsi Variabel Ukuran Organisasi $\left(\mathrm{X}_{3}\right)$

Penilain responden terhadap variabel Ukuran Organisasi $\left(\mathrm{X}_{3}\right)$, menurut klarifikasi tingkatan skor dari masing-masing pernyataan Ukuran Organisasi dijelaskan pada tabel berikut ini:

Tabel 6. Distribusi Frekuensi Jawaban Responden Terhadap Ukuran Organisasi

\begin{tabular}{|c|c|c|c|c|c|c|c|c|c|c|c|}
\hline \multirow{2}{*}{$\begin{array}{c}\text { Nomor } \\
\text { Pernyataan }\end{array}$} & \multicolumn{11}{|c|}{ Jawaban Responden } \\
\hline & 5 & $\%$ & 4 & $\%$ & 3 & $\%$ & 2 & $\%$ & $\mathbf{1}$ & $\%$ & Total \\
\hline 1 & 6 & 12 & 30 & 60 & 9 & 18 & 5 & 10 & - & - & 50 \\
\hline 2 & 5 & 10 & 13 & 26 & 24 & 48 & 8 & 16 & - & - & 50 \\
\hline 3 & 8 & 16 & 28 & 56 & 12 & 24 & 2 & 4 & - & - & 50 \\
\hline 4 & 7 & 14 & 33 & 66 & 6 & 12 & 4 & 8 & - & - & 50 \\
\hline 5 & 7 & 14 & 26 & 52 & 13 & 26 & 3 & 6 & 1 & 2 & 50 \\
\hline Rata-Rata & 6.6 & 13.2 & 26 & 52 & 12.8 & 25.6 & 4.4 & 8.8 & 1 & 2 & 50 \\
\hline
\end{tabular}

Sumber: Lampiran 3

Berdasarkan data Tabel 6 di atas, dapat diketahui bahwa penilaian terbanyak responden terhadap variabel Ukuran Organisasi setuju, yaitu dengan presentasi jawaban pada indikator Memiliki total asset lebih dari Rp. 5 milyar sebesar 60\%, indikator Unit kegiatan yang memiliki kekayaan bersih lebih besar dari Rp. 200 juta sebesar 26\%, indikator Memiliki pekerja di atas 2000 orang sebesar 56\%, indikator Rotasi pegawai dilakukan secara rutin sesuai aturan sebesar $66 \%$ dan indikator Memiliki beberapa unit kegiatan sebesar $26 \%$. dari presentase masing-masing indikator diperoleh rata-rata sebesar $52 \%$ pada penilaian kriteria jawaban setuju bahwa Ukuran Organisasi pada Perangkat Daerah (OPD) di Kabupaten Lumajang baik dan sesuai.

Deskripsi Variabel Kinerja Sistem Informasi Akuntansi (Y)

Penilain responden terhadap variabel Kinerja Sistem Informasi Akuntansi (Y), menurut klarifikasi tingkatan skor dari masing-masing pernyataan Kinerja Sistem Informasi Akuntansi dijelaskan pada tabel berikut ini: 
Tabel 7. Distribusi Frekuensi Jawaban Responden Terhadap Kinerja Sistem Informasi Akuntansi

\begin{tabular}{|c|c|c|c|c|c|c|c|c|c|c|c|}
\hline \multirow{2}{*}{$\begin{array}{c}\text { Nomor } \\
\text { Pernyataan }\end{array}$} & \multicolumn{11}{|c|}{ Jawaban Responden } \\
\hline & 5 & $\%$ & 4 & $\%$ & 3 & $\%$ & 2 & $\%$ & 1 & $\%$ & Total \\
\hline 1 & 11 & 22 & 27 & 54 & 12 & 24 & - & - & - & - & 50 \\
\hline 2 & 9 & 18 & 25 & 50 & 16 & 32 & - & - & - & - & 50 \\
\hline 3 & 7 & 14 & 31 & 62 & 12 & 24 & - & - & - & - & 50 \\
\hline 4 & 7 & 14 & 28 & 56 & 12 & 24 & 3 & 6 & - & - & 50 \\
\hline 5 & 14 & 28 & 32 & 64 & 4 & 8 & - & - & - & - & 50 \\
\hline Rata-Rata & 9.6 & 19.2 & 28.6 & 57.2 & 11.2 & 22.4 & 3 & 6 & & & 50 \\
\hline
\end{tabular}

Sumber: Lampiran 3

Berdasarkan data Tabel 7 di atas, dapat diketahui bahwa penilaian terbanyak responden terhadap variabel Kinerja Sistem Informasi Akuntansi setuju, yaitu dengan presentasi jawaban pada indikator Kepuasan pemakai sistem informasi pada isi SIA sebesar 54\%, indikator Kepuasan pemakai sistem informasi pada akurasi SIA sebesar 50\%, indikator Kepuasan pemakai sistem informasi pada format SIA sebesar $62 \%$, indikator Banyaknya penggunaan/durasi sebesar $56 \%$ dan indikator Kerutinan penggunaan sebesar $64 \%$. dari presentase masing-masing indikator diperoleh rata-rata sebesar 57,2\% pada penilaian kriteria jawaban setuju bahwa Kinerja Sistem Informasi Akuntansi pada Organisasi Perangkat Daerah (OPD) di Kabupaten Lumajang baik dan sesuai. Hasil perhitungan yang lebih jelas dapat di lihat pada Tabel 7.

Adapun hasil Hipotesi dapat diringkas seperti pada table sebagai berikut: Uji t adalah suatu uji untuk pengaruh secara parsial variabel bebas terhadap variabel terikat. Hasil uji t sebagai berikut:

Tabel 8. Hasil Uji t

\begin{tabular}{lccc}
\hline \multicolumn{1}{c}{ Variabel } & t tabel & t hitung & Sig \\
\hline Partisipasi Pemakai Sistem Informasi $\left(X_{1}\right)$ & 1,671 & 2,390 & 0,021 \\
Kemampuan Pemakai Sistem $\left(X_{2}\right)$ & 1,671 & 2,662 & 0,011 \\
Ukuran Organisasi $\left(X_{3}\right)$ & 1,671 & 2,335 & 0,024 \\
\hline
\end{tabular}

Sumber: Lampiran 7

Berdasarkan Tabel 8 tersebut dapat diketahui besar dari pengaruh masing-masing variabel independen terhadap variabel dependen sebagai berikut :

1. Partisipasi Pemakai Sistem Informasi $\left(\mathrm{X}_{1}\right)$ terhadap variabel Kinerja Sistem Informasi Akuntansi $(\mathrm{Y})$ Berdasarkan Tabel 4.12 dapat dilihat bahwa Tingkat signifikansi $(\alpha)$ dari variabel Partisipasi Pemakai Sistem Informasi $\left(\mathrm{X}_{1}\right)$ adalah 0,021 < 0,05 dan nilai $\mathrm{t}$ hitung 2,390 > t table 1,671. Hal ini berarti Partisipasi Pemakai Sistem Informasi berpengaruh signifikan terhadap Kinerja Sistem Informasi Akuntansi ( $\mathrm{H}_{1}$ diterima).

2. Kemampuan Pemakai Sistem $\left(\mathrm{X}_{2}\right)$ terhadap variabel Kinerja Sistem Informasi Akuntansi $(\mathrm{Y})$

Berdasarkan Tabel 4.12 dapat dilihat bahwa Tingkat signifikansi $(\alpha$ ) dari variabel Kemampuan Pemakai Sistem $\left(\mathrm{X}_{1}\right)$ adalah 0,011 < 0,05 dan nilai t hitung 2,662 > t table 1,671. Hal ini berarti Kemampuan Pemakai Sistem berpengaruh signifikan terhadap Kinerja Sistem Informasi Akuntansi ( $\mathrm{H}_{2}$ diterima).

3. Ukuran Organisasi $\left(\mathrm{X}_{3}\right)$ terhadap variabel Kinerja Sistem Informasi Akuntansi $(\mathrm{Y})$

Berdasarkan Tabel 4.12 dapat dilihat bahwa Tingkat signifikansi $(\alpha)$ dari variabel Ukuran Organisasi $\left(\mathrm{X}_{3}\right)$ adalah 0,024<0,05 dan nilai t hitung 2,335 > t table 1,671. Hal ini berarti Ukuran Organisasi berpengaruh signifikan terhadap Kinerja Sistem Informasi Akuntansi $\left(\mathrm{H}_{2}\right.$ diterima)

\section{Simpulan dan saran}

Berdasarkan hasil analisis dan pembahasan yang telah peneliti jelaskan maka dapat disimpulkan yakni Hasil pengujian regresi berganda atas pengaruh Partisipasi pemakai sistem informasi terhadap kinerja SIA menunjukkan hubungan yang positif signifikan. Ini membuktikan bahwa Partisipasi pemakai sistem informasi yang baik akan meningkatkan kinerja SIA. Hasil pengujian regresi berganda atas pengaruh Kemampuan pemakai sistem terhadap kinerja SIA menunjukkan hubungan yang positif signifikan. Ini membuktikan bahwa Kemampuan pemakai sistem yang baik akan meningkatkan kinerja 
SIA. Hasil pengujian regresi berganda atas pengaruh Ukuran organisasi terhadap kinerja SIA menunjukkan hubungan yang positif signifikan. Ini membuktikan bahwa Ukuran organisasi yang baik akan meningkatkan kinerja SIA.

Bagi Pihak Instansi OPD Kabupaten Lumajang agar terus mempertahankan persepsi karyawan atas Partisipasi pemakai sistem informasi yang dirasa telah sangat baik. Pihak Instansi OPD Kabupaten Lumajang agar terus mempertahankan persepsi karyawan atas Kemampuan pemakai sistem yang dirasa telah sangat baik. Pihak Instansi OPD Kabupaten Lumajang agar terus mempertahankan persepsi karyawan atas Ukuran organisasi yang dirasa telah sangat baik. Bagi peneliti selanjutnya dapat menambahkan variabel-variabel lainnya untuk mengetahui faktor-faktor yang mempengaruhi kinerja SIA, selain itu peneliti selanjutnya juga menambah jumlah variabel dengan melakukan penelitian di instansi lainnya yang berbeda dengan membandingkan hasil penelitian sebelumnya, untuk menganalis apakah variabel lainnya juga dapat berpengaruh atau tidak berpengaruh dengan memberikan analisisnya mengenai hasil data yang diperoleh.

\section{Daftar Rujukan}

Amrul, Sadat dan Syar'ie, Ahyadi, 2005, Analisis Beberapa Faktor Yang Berpengaruh Terhadap Proses Pengembangan Kualitas Sistem, Solo: Simposium Nasional Akuntansi VIII

Bodnar, George H, \& Hopwood, William S, 2010, Accounting Information System, Tenth Edition, Pearson Education inc, Upper saddle River, New Jersey

Bonner, S. E. \& Sprinkle. 2002. A Model of The Effects of Audit Task Complexity, Accounting, Organizations and Society., 19 (3): 213-234.

Campbell, N. A, 2000, International Student Edition Biology, Singapore : Addison Wesley Longman, Inc

Choe, Jong-Min, 1996, The Relationship Among Performance of Accounting Information System, Influence factor, and Evolution Level of Information System, Journal Management Information System, Vol 12 iss,

Elsa. 2010. Pengaruh Profitabilitas, Financial Leverage, dan Pertumbuhan Perusahaan terhadap Tindakan Perataan Laba. Jurnal Akuntansi 1(3): 1-23.

Fung Jen.2008. “Faktor-Faktor Yang Mempengaruhi Kinerja Sistem Informasi Akuntansi,"Jurnal Bisnis dan Akuntansi Volume IV No.2

Goodhue, D.I 1995. “Task -Technology and Individual Performance”. Mis Quarterly, Juni 213-236.

Ghozali, Hapsari, 2006, Pengaruh Teknologi Informasi Berbasis Sumber Daya Terhadap Kinerja Perusahaan, Jurnal Maksi, Vol,6 No,1 (60-68).

Ghozali, Imam. 2013. Aplikasi Analisis Multivariate dengan Program IBM SPSS 19. Semarang: UNDIP.

Ginzberg, M.J. April 1981. "Early Diagnosis of Implementation Failure: Priopmising Result and Unanswered Question". Management Sciences. Vol. 27, No. 4

Gomes, Cardoso, 2009, Manajemen Sumber Daya Manusia, Edisi kelima,Yogyakarta

Hasibuan, 2006, Manajemen Sumber Daya Manusia, Jakarta: BumiAksara

Hunton \& Kenneth (1994). Management Information Systems: Managing the Digital Firm, 10th edition. Pearson Education, Inc., New Jersey

Irawati, Wijayanti, 2005, Pengaruh Partisipasi Pemakaidan Kepuasan Pemakai Terhadap Kinerja Sistem Informasi, Skripsi, Fakultas Ekonomi, Universitas Muhamadiyah Malang 
Jiambalvo, J. dan Pratt, J. 1982. Task Complexity and Leadership Effectiveness in CPA Firms. The Accounting Review, Vol LVII, No.4.

Jogiyanto , 2008, Sistem Informasi Keperilakuan, CV Andi Offset, Yogyakarta

Komara, 2005, Analisis Faktor Faktor Yang Mempengaruhi Kinerja Sistem Informasi Akuntansi, SNAVIII, Solo

Lau Elfreda Aplonia, 2005, Pengaruh partisipasi Pemakai Terhadap Kepuasan pemakai dalam Pengembangan Sistem Informasi dengan Lima Variabel Moderating, Jurnal riset Akuntansi Indonesia

Lawrence, M dan Choe. 1996. “Exploring Individual User Satisfaction Within User Led Development.” MIS Quartely. June.

Luciana Spica Almalia \& Irmaya Briliantine, 2007, Analisis Faktor Faktor Yang Mempengaruhi Kinerja Sistem Informasi Akuntansi Pada Bank Umum Pemerintah di wilayah Surabya dan Sidoarjo, STIE Perbanas Surabaya

McLeod Jr, Raymond, George P, Schell, 2007, Sistem Informasi Manajemen, PT, Indeks, Jakarta

McKeen dkk. (1994). Biochemistry: The Moleculer Basis of Life. New York: McGraww-Hill.

Mohd-Sanusi, Z. and Iskandar, T.M. 2007. Audit Judgment Performance: Assessing the Effect of Performance Incentives, Effort and Task Complexity. Managerial Auditing Journal, 22: 34-52.

Muntoro R.K. 1994. "The Use of Organization Behavior Methods in The Development of Computerized Accounting System in Indonesia: An Attidudial Survey." Ph.D. Dissertation. Accountancy Development in Indonesia Publication.

Nugroho, Eko, 2008, Peran Sistem Informasi Dalam Menciptakan Keunggulan Daya Saing, KELOLA No, 6/III Mei 2008

Numaker \& Ralph, Akuntansi Pemerintahan, edisi 4, Jakarta: Erlangga, 1996.

Nura Ruslia, 2011, Analisis Faktor-Faktor Yang Berpengaruh Terhadap Kinerja Sistem Informasi Akuntansi, Skripsi, Universitas Pasundan

Pratomo et.al. 2009. Reksa Dana Solusi Perencanaan Investasi di Era Modern. PT. Garamedia Pustaka Utama. Jakarta

Reichheld, F.F \& Izak. (1996), The Loyalty Effect, Harvard Business School Press, Boston, MA.

Robbins, 2005, Organizational Behavior, Elevent Edition, International Edition, Pearson Education inc, San Diego State University, Upper Saddle river, New jersey

Marshall B, \& Steinbart, 2009, Accounting Information System, Eleventh Edition, Prentice Hall

Sadatamrul, 2004, Hubungan Antara Partisipasi Dalam Pemgembangan Sistem Informasi Dengan Perkembangan Penggunaan Teknologi Informasi (Suatu Tinjauan Dengan Dua Faktor Kontijensi), Seminar Nasional Akuntansi VII, 2-3 Desember

Salam, Darma Setyawan, 2007, Manajemen Pemerintahan Indonesia,Jakarta : Djambatan

Sedarmayanti, 2009, Sumber Daya Manusia dan Produktivitas Kerja, Bandung: CV, Mandar Maju

Sekaran, Uma. 2006. Research Methods For Business (Metodologi Penelitian untuk Bisnis). Jakarta: Salemba Empat. 
Setianingsih, I. 2008. "Sistem Pengendalian Internal atas Aktiva tetap pada Fakultas Ekonomi Univesitas Sumtra Utara". Diploma III Fakultas Ekonomi Universitas Sumatra Utara.

Sulistiyani dan Rosidah, 2008, Manajemen Sumber Daya Manusia, Graha Ilmu : Yogyakarta

Sofyandi, Herman, 2008, Manajemen Sumber Daya Manusia, Penerbit: Graha Ilmu, Yogyakarta

Prajitno, 2006, Analisis faktor-faktor Yang Berpengaruh Terhadap Kinerja SIA Dengan Kompleksitas Tugas sebagai Variabel Moderating, Jurnal Akuntansi

Sugiyono, 2008, Metode penelitian Bisnis, ed, Revisi, Cetakan Delapan Belas, CV, Alafabetha, Bandung

Supomo dan Indriantoro, 2009, Pengaruh Partisipasi Terhadap Kepuasan Pemakai Dalam Pengembangan Sistem Informasi Dengan Kompleksitas Tugas, Kompleksitas Sistem dan Pengaruh Pemakai Sebagai Moderating Variable, Jurnal Analisis Bisnis dan Ekonomi, Vol,2,No, 2 : hal 105-123

Sutrisno, Edy, 2009, Manajemen Sumber Daya Manusia, Edisi Pertama, Cetakan Pertama, Penerbit Kencana, Jakarta

Susanto, 2008, Sistem Informasi Akuntansi, Struktur - Pengendalian - Resiko - Pengembangan, ed, Perdana, Cetakan Pertama, Lingga Jaya, Bandung

Szajna dan Scammell, 1993. "The Effect of Information System User Expectation on Their Performance and Perception". MIS Quartely

Terry, George R, dan Rue, Leslie W, 2005, Dasar-Dasar Manajemen, Jakarta : Bumi Aksara

Veithzal, 2004, Manajemen Sumber Daya Manusia Untuk Perusahaan dari Teori KePraktik. Jakarta : PT. Raja Grafindo Persada.

Wibowo. 2007. Sistem Akuntansi dan Informasi. Terjemahan Marianus Sinaga. Erlangga, Jakarta.

Wijaya. (2004). Kamus Lengkap Inggris-Indonesia. Semarang: Bintang Jaya.

Wilkinson, Joseph, W, 2010, Accounting Information System, Fourth Edition, United States, New York, Jhon Wilwy and Sons Inc

Wood, R. E. 1986. Task Complexity. Definition of The Construct. Organizational Behaviour and Human Decision Process, pp.60-82.

Wahyudi, 2006, Manajemen Sumber Daya Manusia. Penerbit Sulita Bandung

Wulandari. 2006. Karakteristik Good Corporate Governance. Alfabeta. Bandung.. 